\section{The follow-up of patients of sixty-five years of age and younger with acute ischemic stroke and transient ischemic attacks, and elevated D-dimer levels in plasma}

\author{
Magnus Vrethem ${ }^{1}$ and Tomas Lindahl ${ }^{2}$ \\ 'Department of Neurology and \\ Neurophysiology; ' ${ }^{2}$ Department of Clinical \\ Chemistry, University Hospital, \\ Linköping, Sweden
}

\begin{abstract}
D-dimer levels in plasma, a degradation product of fibrin, have been shown to correlate with the severity of ischemic stroke. In order to investigate the outcome of patients with elevated D-dimer we have carried out a follow-up study of patients of 65 years of age and younger with acute ischemic stroke or transient ischemic attacks (TIA) admitted to our stroke unit from 1991 to 1992 . Twenty-two of the 57 patients had elevated D-dimer levels in the plasma. High levels were associated with cardioembolic stroke. On follow-up after a mean of 12 years, 15 patients had died and six patients had suffered another stroke or TIA (three of whom were dead). Ten patients had suffered other cardiovascular events and seven of them were dead. We concluded that high levels of D-dimer in acute ischemic stroke patients on admission were associated with cardioembolic stroke and might have prognostic value for the development of further cardioor cerebrovascular events. Advanced age was found to be an independent risk factor.
\end{abstract}

\section{Introduction}

Hematologic abnormalities appeared to be the main cause of ischemic stroke in approximately one percent of all cases, and derangement of the coagulation process in young people with stroke has been estimated to be about four percent. ${ }^{1}$ The most studied factors in the coagulation process are anticardiolipin antibodies (ACA), which have been recognized as markers for an increased risk of thrombosis, and cerebral ischemia. ${ }^{2}$ Previously we have shown an association between protein $\mathrm{S}$ deficiency and elevated ACA. ${ }^{3}$ D-dimer levels in plasma, a degradation product of fibrin, have been shown to correlate with severity of ischemic stroke ${ }^{4}$ and clinical progression. ${ }^{5}$ We prospectively investigated all acute stroke patients of 65 years of age and younger admitted to our stroke unit between 1991 and 1992 for traditional risk factors and D-dimer. In order to study the outcome and long-term follow-up a questionnaire concerning cerebro- or cardioischemic events was sent to all patients during spring $2004(\mathrm{n}=42)$. Patients not responding to the written questionnaire were contacted by phone. In addition, the medical records from the departments of Neurology and Internal Medicine were checked for all patients.

\section{Materials and Methods}

\section{Patients}

With the approval for this study by the ethics committee of Linköping University Hospital, 502 patients, who were admitted to our stroke unit for suspected acute stroke during 1991 to 1992 , were investigated for the presence of ACA. ${ }^{6}$ Three hundred and ninetyfour of the 502 patients of all age groups had ischemic stroke or transient ischemic attacks (TIA). In 66 patients of 65 years of age or younger ACA, protein $\mathrm{C}$ and $\mathrm{S}$, free protein $\mathrm{S}$, and ATIII were analysed. ${ }^{3}$ In 57 of these 66 patients (36 men and 21 women, mean age $51.4 \mathrm{yr}$, range 24-64 yr), D-dimer was measured as well. Blood samples were taken within 24 hours of admission in the patients. All patients underwent computed tomography of the brain to establish diagnosis. Strokes were classified on the basis of the presence of risk factors, the mode of onset, clinical findings,
Correspondence: Magnus Vrethem, Department of Neurology, University Hospital, S- 58185 Linköping, Sweden. E-mail: magnus.vrethem@lio.se

Key words: D-dimer, stroke, transient ischemic attacks, cerebral ischemia.

Acknowledgements: Mats Fredriksson for statistical help.

Received for publication: 5 April 2009.

Revision received: 15 June 2009.

Accepted for publication: 19 July 2009.

This work is licensed under a Creative Commons Attribution 3.0 License (by-nc 3.0).

CCCopyright M. Vrethem and T. Lindahl 2009

Licensee PAGEPress, Italy

Neurology International 2009; 1:e11

doi:10.4081/ni.2009.e11

and the nature and location of the occluded vessel according to Berger et $a l^{7}{ }^{\text {(cardioem- }}$ bolic: $n=11$, atherothrombotic: $n=11$, lacunar: $\mathrm{n}=19$, TIA: $\mathrm{n}=11$, unknown: $\mathrm{n}=5$ ). In addition, previous stroke, myocardial infarction, and peripheral thrombosis were noted. Symptoms and laboratory signs of infection were recorded. Platelet count, activated partial tromboplastin time (APTT), sedimentation rate (SR), C-reactive protein (CRP), and white blood cell count were measured in all patients. Risk factors were scrutinized in each patient. Carotid Doppler was performed in 49 patients. Triglycerides and cholesterol were examined in 50 patients.

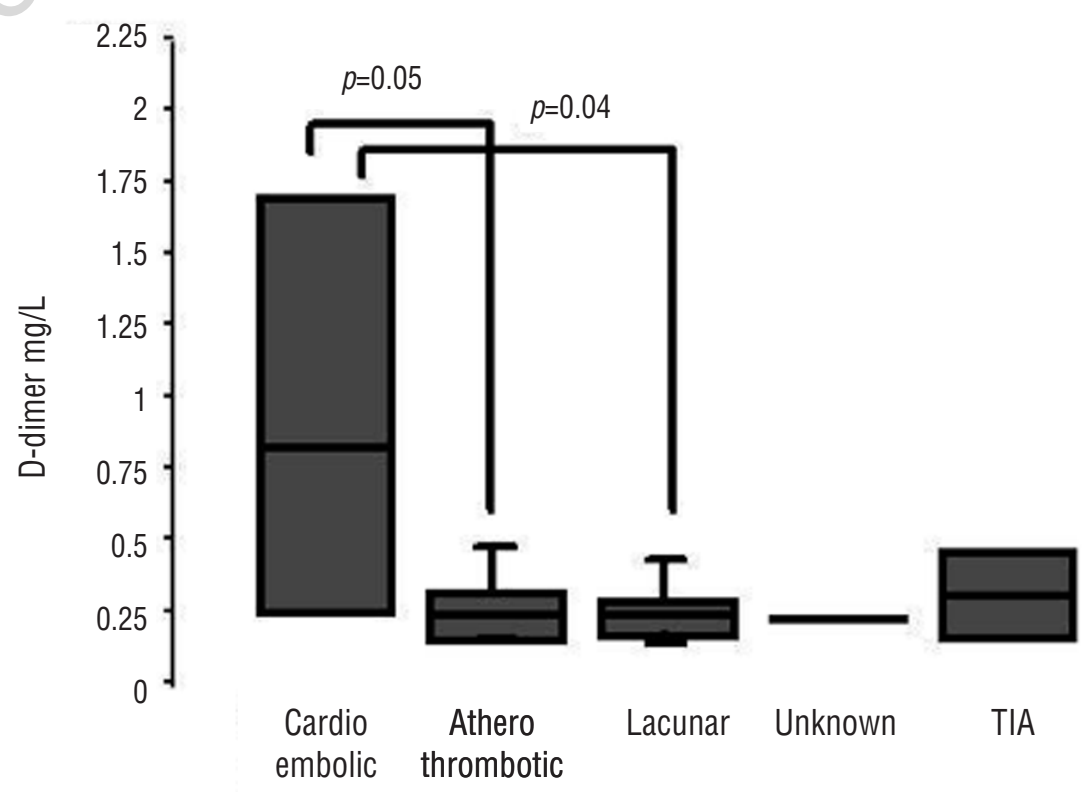

Figure 1. D-dimer levels in relation to stroke subtypes. 
Table 1. Characteristics of patients with elevated and normal D-dimer levels.

\begin{tabular}{|c|c|c|c|c|c|c|c|c|c|}
\hline $\begin{array}{l}\text { Patient } \\
\text { group }\end{array}$ & $\begin{array}{l}\text { Number and } \\
\text { sex (male/ } \\
\text { female) }\end{array}$ & $\begin{array}{l}\text { Age, years } \\
\text { (mean } \\
\text { and range) }\end{array}$ & $\begin{array}{l}\text { Atrial } \\
\text { fibrillation }\end{array}$ & $\begin{array}{l}\text { Diabetes } \\
\text { mellitus }\end{array}$ & Hypertension & $\begin{array}{l}\text { Carotid Doppler } \\
\text { (stenosis } \geq 75 \% \\
\text { or occlusion) }\end{array}$ & $\begin{array}{l}\text { Major/ } \\
\text { minor } \\
\text { stroke }\end{array}$ & $\begin{array}{l}\text { Subtype } \\
\text { of stroke } \\
\text { (number } \\
\text { of patients) }\end{array}$ & $\begin{array}{l}\text { Infectious } \\
\text { parameters } \\
\text { (number of } \\
\text { elevated tests) }\end{array}$ \\
\hline $\begin{array}{l}\text { Elevated } \\
\text { D-dimer } \\
\text { levels }\end{array}$ & $\begin{array}{c}22 \\
(14 / 8)\end{array}$ & $\begin{array}{c}52.3 \\
(30-65)\end{array}$ & 0 & 2 & 6 & 5 & $9 / 13$ & $\begin{array}{l}\text { cardioembolic } 4 \\
\text { atherothrombotic } 7 \\
\text { lacunar } 8 \\
\text { unknown } 1 \\
\text { TIA } 2\end{array}$ & $\begin{array}{l}\text { SR } 7 \\
\text { CRP } 3 \\
\text { WBC } 8\end{array}$ \\
\hline $\begin{array}{l}\text { Normal } \\
\text { D-dimer } \\
\text { levels }\end{array}$ & $\begin{array}{c}35 \\
(21 / 14)\end{array}$ & $\begin{array}{c}52.3 \\
(25-65)\end{array}$ & 3 & 4 & 11 & 0 & $8 / 27$ & $\begin{array}{l}\text { cardioembolic } 7 \\
\text { atherothrombotic } 4 \\
\text { lacunar } 11 \\
\text { unknown } 4 \\
\text { TIA } 9\end{array}$ & $\begin{array}{l}\text { SR } 5 \\
\text { CRP } 4 \\
\text { WBC } 8\end{array}$ \\
\hline
\end{tabular}

SR: sedimentation rate $\left(\mathrm{n}<20 \mathrm{~mm}\right.$ for men and $<12 \mathrm{~mm}$ for women), CRP: C-reactive protein $(\mathrm{n}<10)$, WBC: white blood cell count $\left(\mathrm{n}<10 \times 10^{9} / \mathrm{L}\right)$.

\section{Laboratory methods}

D-dimer was measured utilizing an automated micro-latex assay, Tina-quant ${ }^{\circledR}$, from Boehringer-Mannheim (Darmstadt, Germany) using a Hitachi 911 analyzer, manufactured by Hitachi (Kobe, Japan). Normal values were $<0.15 \mathrm{mg} / \mathrm{mL}$, which was the lower detection limit.

\section{Statistical methods}

Student's $t$-test was used for analyses of Ddimer levels in relation to the type of stroke. The $\chi^{2}$-test was used to compare groups of patients with elevated or normal D-dimer levels. A multivariate logistic regression analysis was used to compare risk factors in patients with later cerebro- or cardiovascular events compared to patients without later events. A $p$-value of $\leq 0.05$ was judged as significant.

\section{Results}

Elevated D-dimer levels were found in 22 of the 57 patients (mean $0.41 \mathrm{mg} / \mathrm{mL}$, range 0.15 2.02) (Table 1). One of the patients had a previous TIA and one a myocardial infarction. Three patients were found to have a carotid stenosis of $\geq 75 \%$ and two a carotid occlusion. We found significantly elevated D-dimer levels in cardioembolic stroke as compared to atherothrombotic and lacunar stroke (Figure 1). There were more patients with a major than a minor stroke in the group with elevated D-dimer levels (9/13) compared to the group with normal D-dimer levels (8/27), although this difference was not statistically significant ( $p=0.15, \chi^{2}$-test) (Table 1$)$. The mean value for patients with major stroke was $0.47 \mathrm{mg} / \mathrm{mL}$ (range 0.15-2.02) compared to patients with minor stroke: $0.36 \mathrm{mg} / \mathrm{mL}$ (range $0.16-1.42$ ), not a statistically significant difference. On follow-up after a mean of 12 years, 15 patients

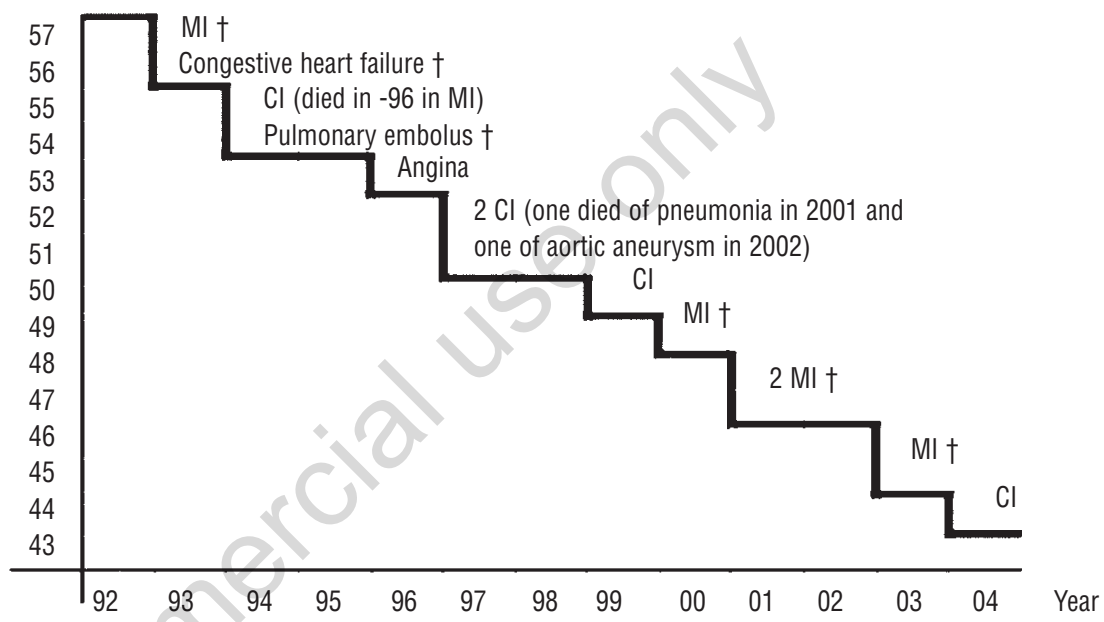

Figure 2. Kaplan-Meyer graph of cerebro- and cardiovascular events during follow-up. MI: myocardial infarction; CI: cerebral infarction; TIA: transitory ischemic attack; $\dagger$ : dead.

had died (seven from cardiovascular events, three from pneumonia, two from cancer, one after a pulmonary embolus, one from amyloidosis, and one from multi-organ failure). Five patients had suffered another ischemic stroke (three of whom were dead) and one had suffered a TIA. Ten had suffered other cardiovascular events (myocardial infarction, angina, congestive heart failure, aortic aneurysm), seven of them were dead (Figure 2).

There was a trend for patients with elevated levels of D-dimer at the time of sampling after the stroke to be more prone to develop further cardio- or cerebrovascular events at follow-up (eight of 22 patients compared to seven of 35 of those with normal D-dimer levels; $p=0.17$, $\chi^{2}$-test and Pearson's correction). Mean values were slightly higher for patients who had further cardio- and cerebrovascular events: 0.47 $\mathrm{mg} / \mathrm{mL}$ (range 0.19-1.42) compared to 0.37 $\mathrm{mg} / \mathrm{mL}$ (range $0.15-2.02$ ) for those without further events during follow-up. When using a multivariate analysis with logistic regression, however, this variable was not an independent risk factor (odds ratio $2.5, p=0.19$ ). The 15 patients with later cerebro- or cardiovascular events were significantly older: 60.4 years compared to the 42 patients without later events aged 49.5 years (odds ratio $1.2, p=0.01$ ). Other risk factors (cardiac arrhythmia, diabetes, high blood pressure, carotid stenosis, smoking, high cholesterol, previous TIA or stroke, or angina) were not independently correlated to later cerebro- or cardiovascular events.

\section{Discussion}

We found an association between elevated D-dimer levels and cardioembolic stroke, which was in agreement with reports of other researchers. ${ }^{4,8}$ Elevated levels in patients with acute ischemic stroke have been found for up to four weeks in some persons. ${ }^{9}$ In addition, 
plasma concentrations of D-dimer have been reported to be an indicator of recurrent embolization in patients suffering from cardioembolic stroke. ${ }^{10}$ A trend toward an increased risk of recurrent cardio- and cerebrovascular events on follow-up after a mean of 12 years in patients with elevated D-dimer levels was noted (eight of 22 patients compared to seven of 35 with normal D-dimer levels); however, the difference was not statistically significant $(p=0.17)$. Patients with high D-dimer, fibrinogen, and CRP have been associated with an increased risk of recurrent cardiovascular events, ${ }^{11}$ which was found in our patients with elevated D-dimer levels (10 had suffered cardiovascular events on follow-up).

In a review, Lowe $(2005)^{12}$ discussed the potential clinical utility of D-dimer testing in the prediction of cardiovascular risk and prophylactic anticoagulation. In addition, D-dimer levels have been shown to predict clinical progression in ischemic stroke. ${ }^{5}$ There are further reports showing no relationship between Ddimer levels and recurrent ischemic stroke. ${ }^{13,14}$ Woodward et al., ${ }^{14}$ however, found that fibrinogen and CRP were risk factors for recurrent ischemic stroke. The severity of the recurrent events in our patients is evident because five of the eight patients died. D-dimer levels were found to be related linearly to stroke severity in 76 consecutive ischemic stroke patients. ${ }^{15}$ Moreover, D-dimer is reported to be a good predictor for identifying patients at high risk for stroke progression, supporting our observation of a severe course for many of the patients with elevated D-dimer levels. ${ }^{5}$ Patients with atrial fibrillation and elevated D-dimer levels are reported to be more prone to develop thromboembolic events. ${ }^{16}$ This conclusion is disputed by others. ${ }^{17}$ In our patients with elevated D-dimer levels, none of them had atrial fibrillation. However, high-grade carotid stenosis $(\geq 75 \%)$ or carotid occlusion was found in five of our patients with elevated D-dimer levels. We concluded that high levels of D-dimer in patients with acute ischemic stroke are associated with cardioembolic stroke and may have a pathogenetic importance for development of further cardio- or cerebrovascular events. Advanced age seems to be an important independent risk factor for further cerebro- or cardiovascular events. Because there were relatively few patients in our study, its prognostic role remains somewhat uncertain and, as suggested by Squizzato et al. ${ }^{18}$ further larger studies are warranted.

\section{References}

1. Hart RG, Kanter MC. Hematologic disorders and ischemic stroke: A selective review. Stroke 1990;21:1111-21.

2. Brey RL, Hart RG, Sherman DG, et al. Antiphospholipid antibodies and cerebral ischemia in young people. Neurology 1990;40:1190-6.

3. Vrethem M, Dahle C, Lindahl T, et al. Association between deficiency of free protein $\mathrm{S}$ and anticardiolipin antibodies in patients $\leq 65$ years of age with acute ischemic stroke and TIA. Eur J Neurol 1998;5: 491-7.

4. Ageno W, Finazzi S, Steidl L, et al. Plasma measurement of D-dimer levels for early diagnosis of ischemic stroke subtypes. Arch Int Med 2002;162:2589-93.

5. Barber M, Langhorne P, Rumley A, et al. Ddimer predicts early clinical progression in ischemic stroke: confirmation using routine clinical assays. Stroke 2006;37:1113-5.

6. Dahle C, Vrethem M, Olsson JE, et al. High levels of anticardiolipin antibodies is an unusual finding in an unselected stroke population. Eur J Neurol 1995;2:331-6.

7. Berger K, Kase CS, Burlng JE. Interobserver agreement in the classification of stroke in the physicians' health study. Stroke 1996;27:238-42.
8. Yamazaki M, Uchiyama S, Maruyama S. Alterations of haemostatic markers in various subtypes and phases of stroke. Blood Coagul Fibrinolysis 1993;4:707-12.

9. Feinberg WM, Bruck DC, Ring ME, et al. Hemostatic markers in acute stroke. Stroke 1989;20:592-7.

10. Takano K, Yamaguchi T, Kato H, et al. Activation of coagulation in acute cardioembolic stroke. Stroke 1991;22:12-6.

11. Smith A, Patterson C, Yarnell J, et al. Which hemostatic markers add to the predictive value of conventional risk factors for coronary heart disease and ischemic stroke? The Caerphilly study. Circulation 2005;112:3080-9.

12. Lowe GD. Fibrin D-dimer and cardiovascular risk. Semin Vasc Med 2005;5:387-98.

13. Squizzato A, Ageno W, Finazzi S, et al. Ddimer is not a long-term prognostic marker following acute cerebral ischemia. Blood Coag Fibrinol 2006;17: 303-6.

14. Woodward M, Lowe GD, Campbell DJ, et al. Associations of inflammatory and hemostatic variables with the risk of recurrent stroke. Stroke 2005;36:2143-7.

15. Berge E, Friis P, Sandset PM. Hemostatic activation in acute ischemic stroke. Thromb Res 2001;101:13-21.

16. Nozawa $\mathrm{T}$, Inoue $\mathrm{H}$, Hirai $\mathrm{T}$, et al. D-dimer level influences thromboembolic events in patients with atrial fibrillation. Int $\mathrm{J}$ Cardiol 2006;28:59-65.

17. Turgut N, Ademir 0, Turgut B, et al. Hypercoagulopathy in stroke patients with nonvalvular atrial fibrillation: hematologic and cardiologic investigations. Clin Appl Thromb Hemost 2006;12:15-20.

18. Squizzato A, Ageno W. D-dimer testing in ischemic stroke and cerebral sinus and venous thrombosis. Semin Vasc Med 2005; 5:379-86. 